\title{
The Colour of Electroplated Golds
}

\author{
David J. Arrowsmith \\ University of Aston in Birmingham, England
}

\begin{abstract}
The origin of the colour of gold and gold alloy electrodeposits is discussed, whether any new colours may be expected, and whether theory may be used to predict the colour of new alloys.
\end{abstract}

Coloured gold electrodeposits are used for a wide range of decorative applications $(1,2)$. Examples of these include jewellery, ornamental trim, spectacle frames, pen clips, bracelets and watchcases.

Component parts are often used in conjunction with each other or in conjunction with wrought gold alloys, and so colour control of gold plating processes and accurate colour matching are essential. Plating processes have been developed to match the colours of most wrought gold alloys (3). Improved plating processes continue to be developed because in addition to exact matching of the colour there are many other desirable requirements of both the deposit and the process itself. Better wear resistance of the deposit and greater latitude of the plating solution to plating variables are just two examples of improvements constantly being sought.

The composition and structure of coloured gold electrodeposits are different from those of wrought gold. The extent of the differences while still retaining accurate colour matching is the subject to be discussed in this article. Also considered are related topics of interest in the development of coloured gold electrodeposits, whether any new colours may be expected, and whether the theory of the colour of gold alloys may be used to predict the colour of new alloys.

\section{The Origin of Colour}

The colourless, 'white' or 'silvery' appearance of metals is due to their high light reflectivity over the whole of the visible spectrum (4). The spectral reflectivity curves of several metals and alloys are shown in Figure 1. Only gold and copper (and alloys of these metals) out of the 67 metals among the 92 naturally occurring elements are significantly coloured. These two metals have a high reflectivity of light at the red end of the visible spectrum only, and have a reddish to yellow colour.

All other metals are substantially white or grey, though where reflectivity varies slightly over the visible spectrum some metals have a very slight tinge of colour. Aluminium and chromium have a faint bluish tinge, and nickel has a faint yellowish tinge. This slight colour tinge may not be noticed in isolation but is apparent when two metals are placed alongside each other because physiologically the human eye is particularly sensitive to colour differences (6).
Some metals appear grey compared with silver owing to lower overall reflectivity (Figure 2). For example, the reflectivity of polished stainless steel is less than 65 per cent and appears a dull grey compared with the brilliance of silver with over 90 per cent reflectivity (4).

The colour of gold can be changed by alloying. Pure gold has a pronounced step (absorption edge) in the reflectivity curve in the green part of the spectrum at a wavelength of about $540 \mathrm{~nm}$ (Figure 3), and the consequent absorption of light at the blue end of the spectrum results in a different colour. Alloying gold with other metals alters the spectral reflectivity curve. Three different kinds of change have been found empirically:

change in the wavelength of the absorption edge,

$\square$ change in the relative reflectivity levels without altering the position of the absorption edge, and

$\square$ the production of an entirely different spectral reflectivity curve by the formation of an intermetallic compound

An example of the first kind is shown in Figure 3 for the gold-silver alloys. As the silver content is progressively increased, the absorption edge moves towards the blue end of the spectrum. At medium silver contents green is strongly reflected in addition to red, orange and yellow, giving the alloy a greenish tinge or greenish yellow colour. At high silver contents (more than 70 per cent (atomic) Ag) the alloy appears essentially white

The behaviour of gold-palladium alloys is different. As the palladium content is progressively increased, the absorption edge does not move, but the reflectivity at the red end of the spectrum progressively falls so that the yellow colour becomes weaker (Figure 4). Nickel decolourises gold in the same way as palladium $(7,9)$.

The formation of an intermetallic compound with a crystal structure different from that of its constituent pure metals results in a spectral response completely different to those of its constituents. $\mathrm{AuAl}_{2}$ has a bright reddish-purple colour and its spectral reflectivity curve (Figure 5) shows red and violet are much more strongly reflected than green and yellow. 


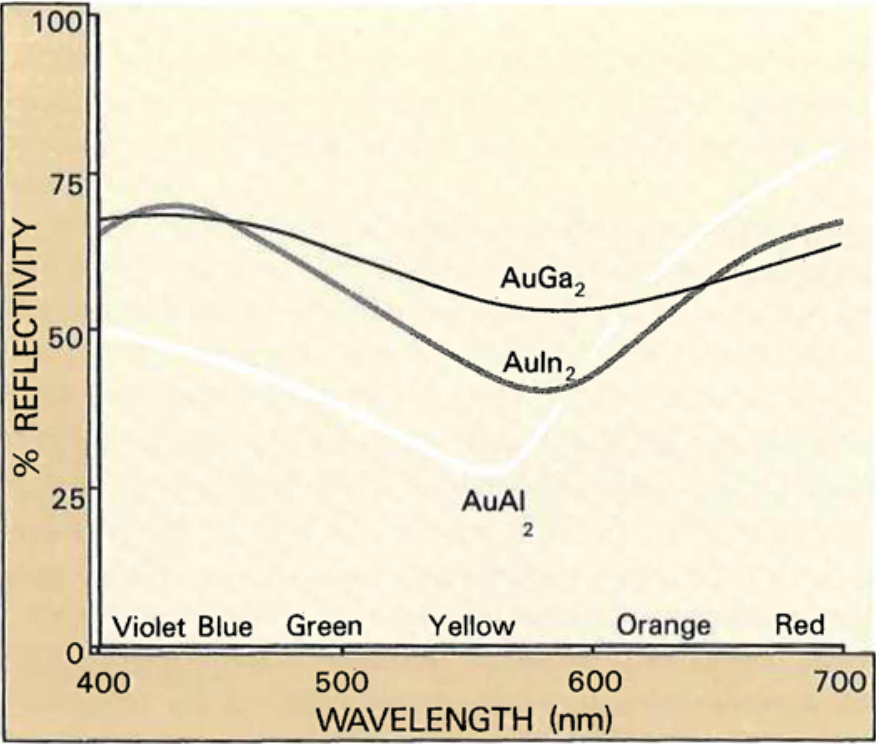

Fig. 5 Spectral reflectivity curves of the three intermetallic compounds,

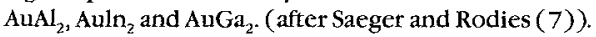

$\mathrm{AuIn}_{2}$ reflects the blue end of the spectrum much more strongly than does $\mathrm{AuAl}_{2}$ and has a bluish colour. $\mathrm{AuGa}_{2}$ has a similar structure to $\mathrm{AuAl}_{2}$ and $\mathrm{AuIn}_{2}$ and a similar spectral reflectivity curve (Figure 5) but the difference in reflectivity across the visible spectrum is much less, and so the colour of $\mathrm{AuGa}_{2}$ is a neutral metallic grey with a faint blue tinge.

Spectral reflectivity curves are relatively easy to obtain experimentally. They show the spectral response of a metal or alloy but do not explain why the reflectivity varies across the visible spectrum. Interpretation of the curves requires an understanding of the interaction of light with the electronic structure of metals. The behaviour of electrons in metals is described by quantum theory in terms of energy levels (13). An isolated metal atom has many possible energy levels of which only the lowest are normally occupied by electrons.

However, when a large number of metal atoms occupy a crystal lattice, the energy levels outside the filled electron shells no longer belong to individual atoms but form a band of energy levels through the lattice because, as required by the Pauli exclusion principle, no two electrons can be in the same energy state. Thus there is a distinction between the core (or bound) electrons within the filled shells around each metal atom, and the conduction (or free) electrons which can move through the lattice on application of an electric field and are responsible for the high electrical conductivity of metals. Since the number of atoms per unit volume of the lattice is very large (of the order of $10^{22} / \mathrm{cm}^{3}$ ), the number of energy levels in the conduction band is very large, and the energy of one differs only very slightly from that of the next.
It takes very little energy to move an electron from one energy level to the next within the conduction band. In this way, photons of incident light are absorbed by electrons. Because there are so many free electrons in the lattice, light can penetrate only a very short distance into a metal. Light of the same wavelength is emitted by the electron on reversion to its former energy level. Thus, the reflectivity of metals is high, but it is not complete because some of the energy absorbed by the electrons is transferred to other electrons and to metal ions by collision and is converted to heat.

The electronic structure of some metals is such that it is possible to move a core electron into the conduction band. The energy needed to raise core electrons in copper from the $3 \mathrm{~d}$ level to the conduction band is that of photons of light at the blue end of the visible spectrum, and the resultant absorption is responsible for the colour of copper. The characteristic colour of gold arises in the same way. Silver, which has a similar electron configuration to copper and gold, behaves in a similar manner but is not coloured since its absorption band is in the ultra-violet part of the spectrum because, compared with either copper or gold, greater energy is needed to lift one of its core electrons to the conduction band.

The influence of alloying and the three kinds of change observed in the spectral reflectivity curves have been interpreted in terms of electronic band structure. Alloying gold with silver broadens the range of energies for interband transitions from core to conduction band levels and moves the absorption edge (Figure 3). On alloying with palladium (Figure 4) the absorption edge remains in the same part of the spectrum but reflectivity at the red end decreases progressively. This has been ascribed to absorption due to a new interband transition introduced by electronic resonance between gold and palladium. The formation of an intermetallic compound results in a completely new electronic band structure and a spectral reflectivity curve (Figure 5) unrelated to those of its constituent metals.

\section{Electroplated Golds}

Electroplated golds have been reviewed comprehensively by Rapson (1). The main metals codeposited with gold to produce coloured golds are: copper for reddish, orange and pink golds; silver and cadmium for greenish yellow golds; and nickel, cadmium and palladium for white golds. Some examples of coloured gold electrodeposits are shown in Figure 6. The colour of the deposit depends on the plating bath composition and plating conditions (1-3), as shown by Dettke (15), for example, when plating gold-copper-cadmium alloy coatings from a commercial solution (Figure 7). The colour depends on the structure of the deposit which can be different from that of thermally prepared alloys of identical composition. The presence of metastable phases, ordering and superlattices 


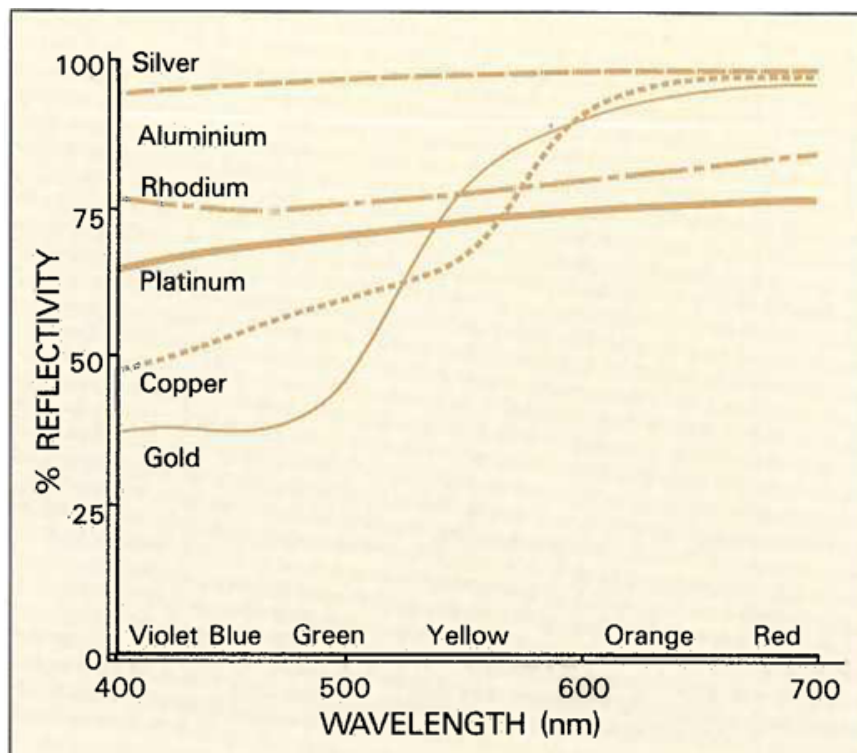

Fig. 1 Spectral reflectivity curves for freshly evaporated mirror coatings of selected metals (28). Below: per cent perpendicular-incidence reflectivity of freshly evaporated mirror coated metals. The reflectivity of a good evaporated mirror is always higher than that of a polished or electroplated surface of the same material. Wavelengths in $\mathrm{nm}$.

\begin{tabular}{ccccccc}
\hline Wavelength & $\mathrm{Al}$ & $\mathrm{Ag}$ & $\mathrm{Au}$ & $\mathrm{Cu}$ & $\mathrm{Rh}$ & $\mathrm{Pt}$ \\
\hline 400 & 92.4 & 95.6 & 38.7 & 47.5 & 77.4 & 66.3 \\
450 & 92.2 & 97.1 & 38.7 & 55.2 & 76.0 & 69.1 \\
500 & 91.8 & 97.9 & 47.7 & 60.0 & 76.6 & 71.4 \\
550 & 91.5 & 98.3 & 81.7 & 66.9 & 78.2 & 73.4 \\
600 & 91.0 & 98.6 & 91.9 & 93.3 & 79.7 & 75.2 \\
650 & 90.5 & 98.8 & 95.5 & 96.6 & $\mathbf{8 1 . 1}$ & 76.4 \\
700 & 89.7 & 98.9 & 97.0 & 97.5 & $\mathbf{8 2 . 0}$ & $\mathbf{7 7 . 2}$ \\
\hline
\end{tabular}

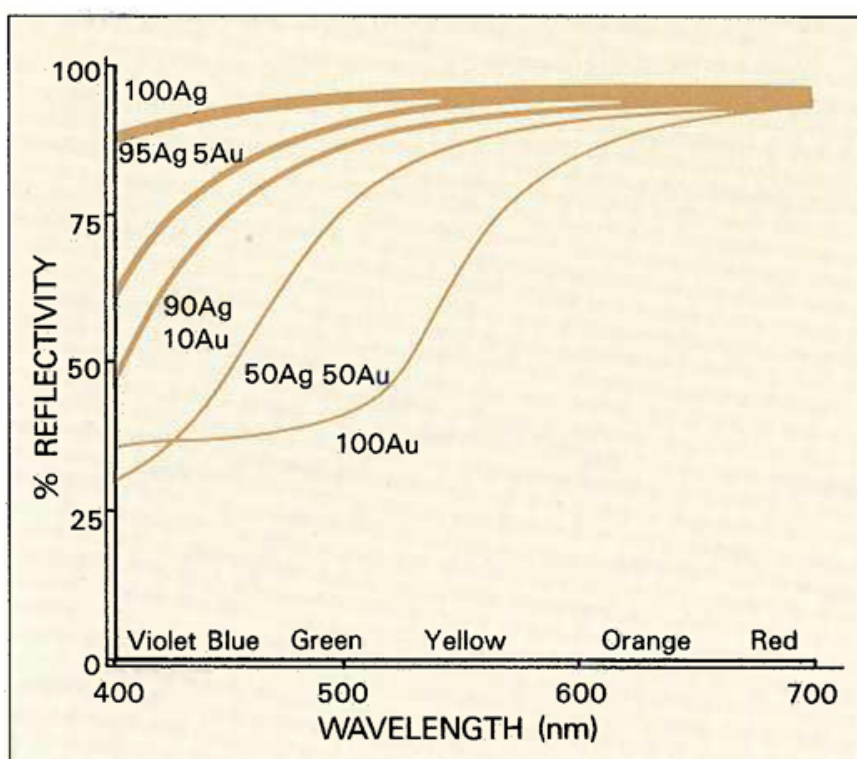

Fig. 3 Spectral reflectivity curves of gold-silver alloys showing the influence of adding silver which shifts the absorption edge towards the blue end of the spectrum (after Fukutani and Sueoka (8)).

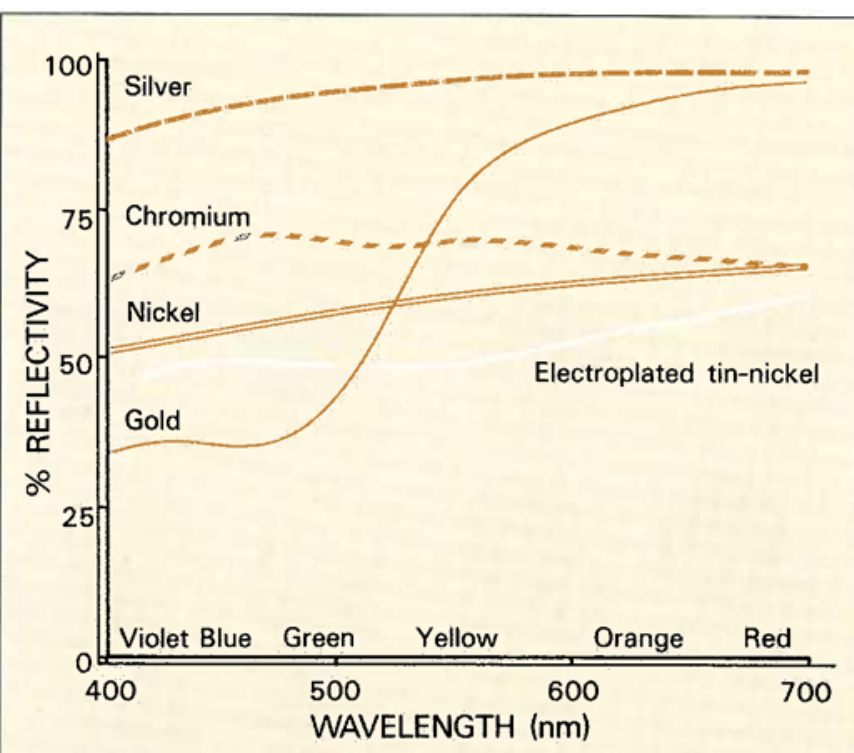

Fig. 2 Spectral reflectivity curves for bright tin-nickel electroplate and for polished silver, chromium, nickel and gold (after Gardam (4) and American Institute of Physics Handbook (28)). Below: Per cent perpendicular-incidence reflectivities of polished metals. Wavelengths in $\mathrm{nm}$

\begin{tabular}{ccccccc}
\hline Wavelength & $\mathrm{Ag}$ & $\mathrm{Au}$ & $\mathrm{Cu}$ & $\mathrm{Ni}$ & $\mathrm{Fe}$ & $\mathrm{Cr}$ \\
\hline 400 & 87.5 & 36.0 & 30.0 & 53.3 & & \\
500 & 95.2 & 41.5 & 43.7 & 59.7 & 56 & 55 \\
600 & 95.6 & 87.0 & 71.8 & 64.5 & 57 & \\
700 & 96.1 & 93.0 & 83.1 & 67.6 & 58 & 56 \\
& & & & & & \\
\end{tabular}

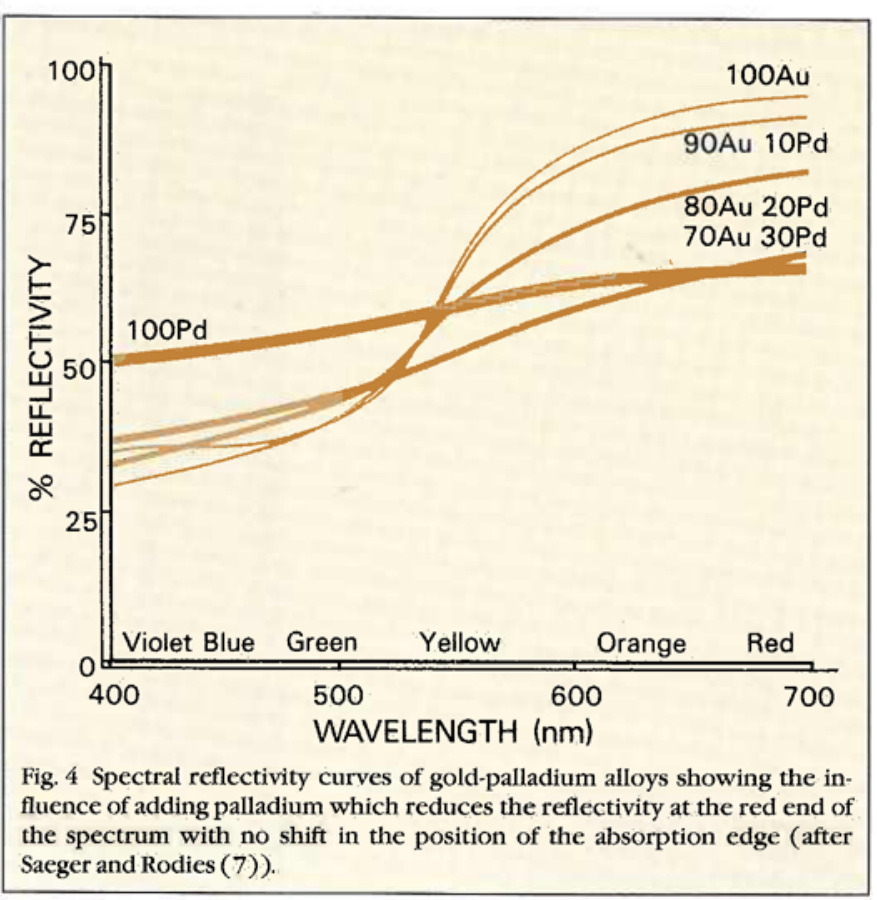


affect the electronic band structure of the alloy and therefore its colour. Köster and Stahl (16) found the influence of short range ordering in AuAg was small, but long range ordering in AuCu and $\mathrm{AuCu}_{3}$ affected the band structure and spectral reflectivity. The change in colour of gold-silver electrodeposits on increasing the silver content of the plating solution is progressive, but the colour of gold-copper electrodeposits on increasing the copper content becomes successively redder, less red and then redder again (17) (Figure 8).

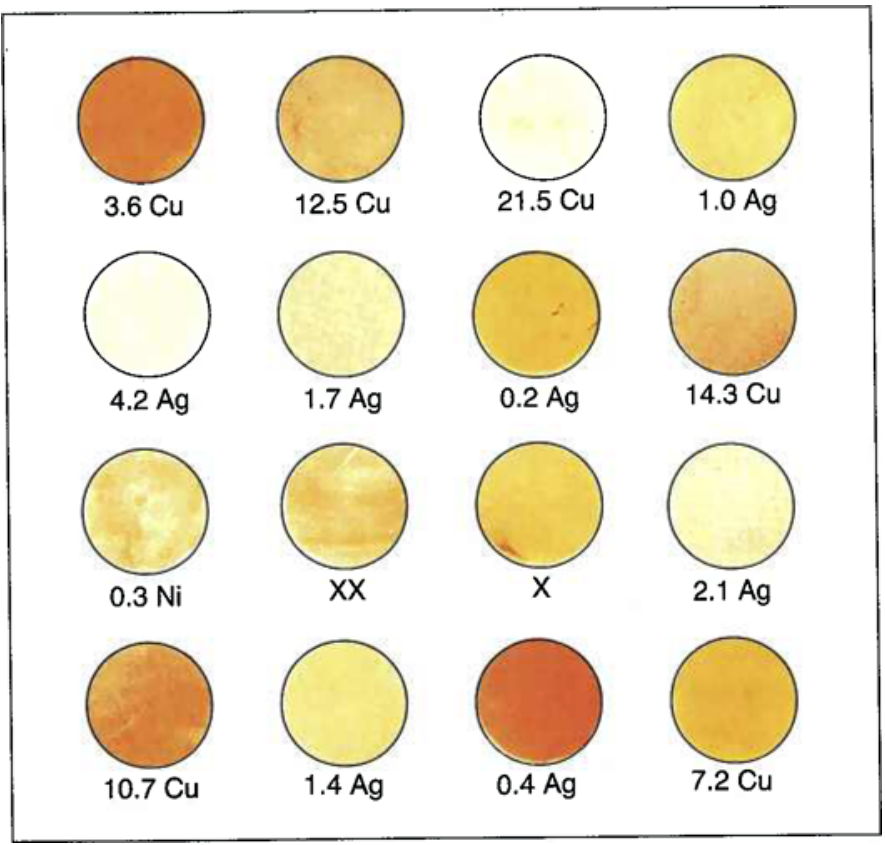

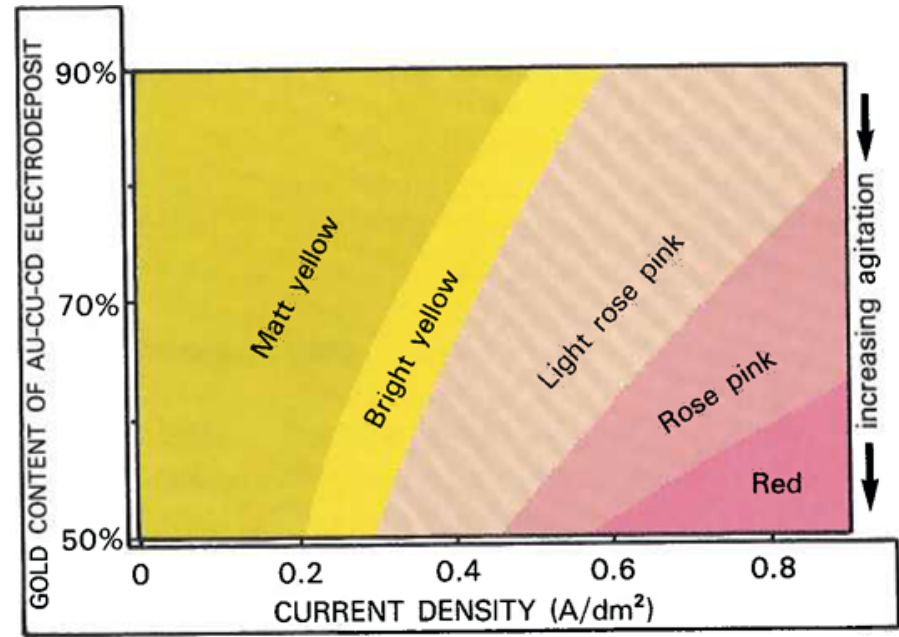

Fig. 7 The colour of Au-Cu-Cd electrodeposits (after Dettke (15)). The colour of the alloy electrodeposits depends on its composition. The com position depends on agitation and current density.

Fig. 6 A selection of electrodeposited golds to show a range of colours Specimen $\mathrm{X}$ was a pure gold electrodeposit plated from a solution containing $2.7 \mathrm{~g} / \mathrm{dm}^{3} \mathrm{KAu}(\mathrm{CN})_{2}+27 \mathrm{~g} / \mathrm{dm}^{3} \mathrm{KCN}$. Specimen XX was a thick matt pure gold electrodeposit plated from a solution containing $3.75 \mathrm{~g} / \mathrm{dm}^{3}$ $\mathrm{KAu}(\mathrm{CN})_{2}+15 \mathrm{~g} / \mathrm{dm}^{3} \mathrm{KCN}$. Alloy gold electrodeposits based on a plating solution containing $2.7 \mathrm{~g} / \mathrm{dm}^{3} \mathrm{KAu}(\mathrm{CN})_{2}+27 \mathrm{~g} / \mathrm{dm}^{3} \mathrm{KCN}$ with silver or copper added as cyanide together with sufficient potassium cyanide to complex. Figures below discs indicate the amount of alloying metal added to the plating solution, e.g. $3.6 \mathrm{Cu}=$ electrodeposit plated from the above potassium gold cyanide solution to which $3.6 \mathrm{~g} / \mathrm{dm}^{3} \mathrm{Cu}$ has been added as cyanide.
Fig. 8 Influence of copper on the position of the absorption edge and on the colour of the gold-copper alloy electrodeposit (17). All other factors being constant.

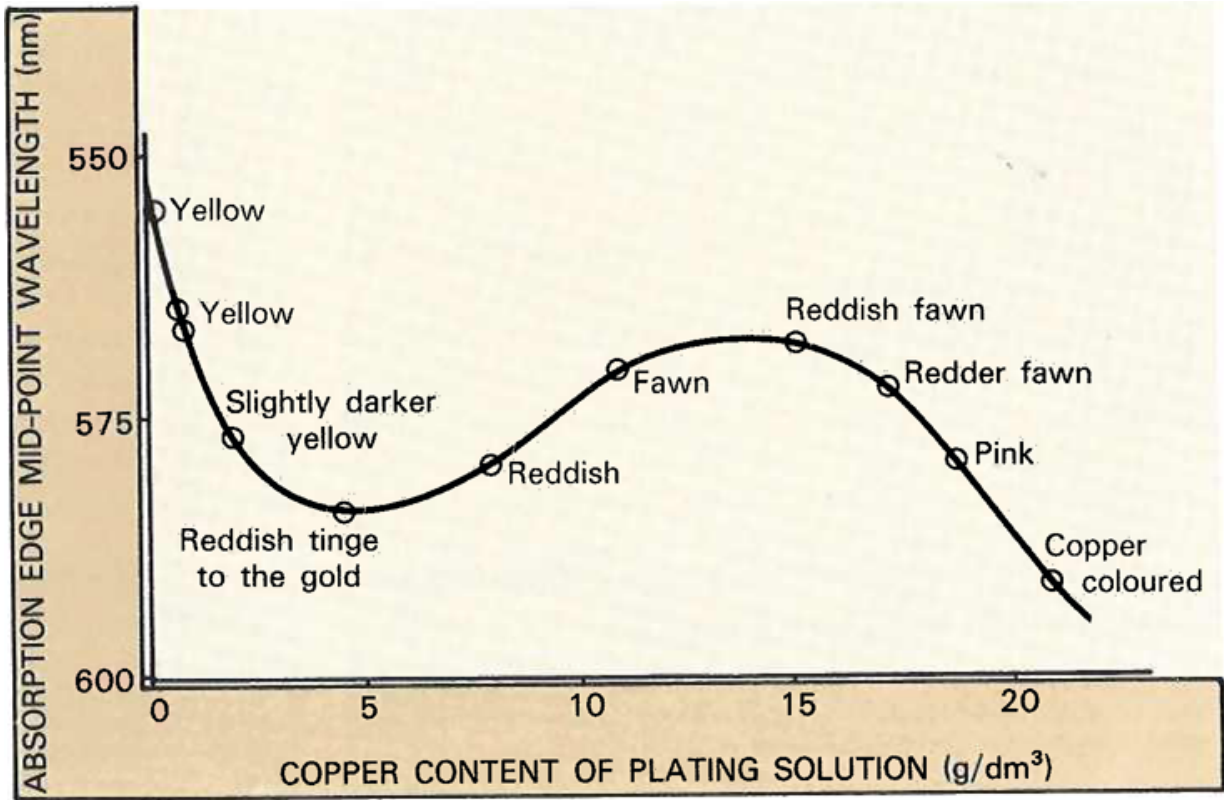

Gold Bull., 1986, 19, (4) 


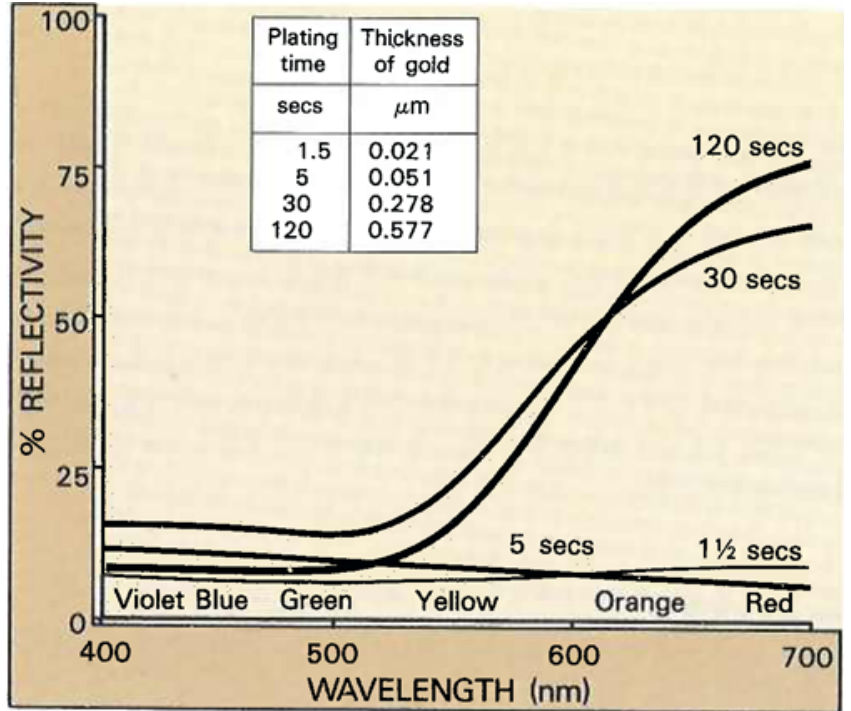

Fig. 9 Spectral reflectivity curves for increasing amounts of gold electrodeposited onto nickel. Thickness of gold calculated from weight increase. pure matt gold plated at $2.5 \mathrm{~A} / \mathrm{dm}^{2}$ at $65^{\circ} \mathrm{C}$ in a potassium gold cyanide solution. Photograph (below) of níckel discs plated for various times indicated in seconds below each disc.

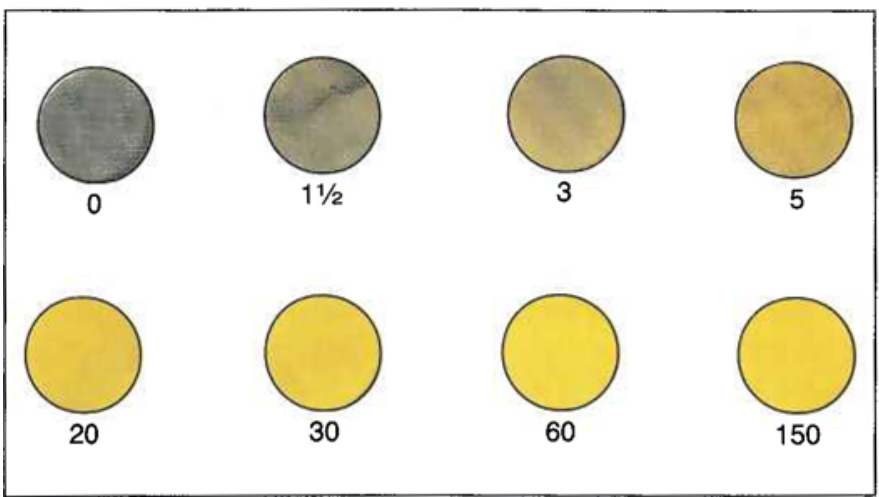

Electroplated golds can be deposited mirror bright, semibright or matt, each of which has a different appearance which can affect colour matching. For example, if a mirror bright deposit has a faint colour, a matt deposit of the same alloy appears more strongly coloured owing to multiple reflections from the rough surface (4).

There is a minimum thickness of gold that has to be deposited before the intrinsic colour of the gold replaces that of the metal substrate (Figure 9). The minimum thickness is about $0.06 \mu \mathrm{m}(60 \mathrm{~nm})$ when bright gold is plated on a polished surface, but can be as much as $0.6 \mu \mathrm{m}$ when matt gold is plated on a rough surface (17). Leobich (18) reported that gold deposits transmitting a noticeable amount of light are between 5 and $40 \mathrm{~nm}$ thick, and light transmission is less than 10 per cent when a thickness of $60 \mathrm{~nm}$ is reached.

\section{Discussion}

Measurements of optical properties were among the first to be used to study the electronic structure of metals and alloys. With the application of quantum mechanics and development of the band theory of metals and alloys, optical properties were related to electronic structure in terms of free conduction electrons and bound core electrons. Alloy theory based on electron density (Hume-Rothery's empirical electron to atom ratios (19)), failed to progress beyond a few relatively simple alloy systems, was unable to aid interpretation of more complex alloys, and was unable to predict alloy behaviour. Spectroellipsometry (20) and X-ray and UV photoelectron spectroscopy (21) have increased the accumulated knowledge of the fine detail of the band structure of metals and alloys, but, far from providing a fundamental explanation of alloying, the measurements reveal increased complexity of electronic structure and uncertainty of electron behaviour. It is hoped that attempts to interpret the detailed photoemission data will eventually lead to an understanding of the underlying fundamental physical behaviour. However, it is still considered that the optical properties of metals and alloys, the high reflectivity, spectral response and colour are electronic in origin.

Although it is not yet possible to use solid state theory to predict the colour of metals and alloys, knowledge from the systematic study of the spectral responses of gold alloys, together with their interpretation in terms of band structure, is valuable in assessing the extent of colour possibilities in gold alloys. The limits of changing the colour of gold by alloying are clear from the three kinds of change exemplified by the alloying of gold with:

silver (Figure 3) which shifts the absorption edge,

$\square$ palladium (Figure 4 ) which reduces the reflectivity, and

$\square$ aluminium (Figure 5) which forms an intermetallic compound.

Almost all alloying of gold reduces the intensity of the colour. Apart from slight colour tinges, the search for a new colour is likely to be successful only if a new intermetallic compound of gold is discovered. Of the large number of gold intermetallics, only $\mathrm{AuAl}_{2}$ and $\mathrm{AuIn}_{2}$ are significantly coloured. Their colour is due to their electronic band structure giving absorption in the visible spectrum in a part significantly different from that of its constituents. If a new compound could be electrodeposited, as there was in the case of $\mathrm{SnNi}$, a new coloured gold 
could be discovered. Electroplated tin-nickel was first described (22) as having a most pleasing rose-purple colour totally devoid of the blueness associated with chromium and the yellowness associated with nickel, but the spectral reflectivity curve (Figure 2) shows the relatively low reflectivity of the alloy which is more accurately described as grey tinged with mauve pink. Its colour is due to a metastable intermetallic compound which is only formed on electrodeposition and not in thermally produced tin-nickel alloys (23). New coloured gold electrodeposits are possible though their formulation cannot be predicted. According to a recent patent (24), violet coloured gold-copper-bismuth alloys can be electrodeposited from a solution containing a water-soluble bismuth complex.

Heat treatment of electroplated golds can alter the colour if a second phase is precipitated, or if a metastable phase transforms to one or more stable phases with different electron band structures. A colour change from reddish copper to yellowish gold has been observed in $\mathrm{AlCu}_{3}$ on cooling through its martensitic transformation temperature (25).

Other ways of changing the colour produce only slight changes. The influences of pressure and lattice spacing on band structure are at most a second order effect (26). Annealing heavily deformed AgAu alloy moved the absorption edge by $5 \pm 4 \mathrm{~nm}$ towards the blue end of the spectrum (27). As no such effect was observed in the pure metals, silver and gold, the shift was considered to be either short range ordering or migration of silver to the surface during annealing.

The spectral reflectivity of electrodeposited pure indium is slightly dominant in the blue region (29). The colour of electroplated gold-indium alloys depends on the alloy composition. An alloy containing 68 per cent gold has a flat spectral curve, whereas at lower gold contents there is a slight tendency to blue dominance. With increasing gold content (above 70 per cent) the red end of the spectrum becomes more and more predominant (29). Electroplated gold-indium of composition equivalent to the intermetallic compound $\mathrm{AuIn}_{2}$ is dull and appears grey (29).

\section{Conclusions}

Even with the accumulating electron spectrographic data on the detailed band structure of metals and alloys, it is not possible yet to predict the electronic structure, spectral response or colour of a particular alloy.

The systematic development of gold alloy electroplating solutions has been successful in producing coloured golds with a combination of other desired properties. This trend is likely to continue and carries with it the possibility of a chance discovery of a new coloured gold-alloy electrodeposit. However, this possibility is remote.

\section{References}

1 W.S. Rapson and T. Groenewald, 'Gold Usage', Acadamic Press, London, 1978

2 F.H. Reid and W. Goldie, 'Gold Plating Technology', Electrochemical Publications Ltd., Ayr, Scotand, 1974

3 A. Brenner, 'Electrodeposition of Alloys', Academic Press, New York and London, 1963 , Vol. 2

4 G.E. Gardam, Iranls. Inst. Met. Finish., 1966, 44, 186-188

5 E.F.I. Roberts and K.M. Clarke, Gold Bull, 1979, 12, (1),9-19

6 G.J. Chamberlin and D.G. Chamberlin, "Colour, - Its Measurement, Computation and Application', Heyden, London, Philadelphia and Rheine, 1980

7 K.E. Saeger and J. Rodies, Gold Bull., 1977, 10,(1), 10-14

$8 \mathrm{H}$. Fukutani and O. Sueoka, 'Optical Properties of Ag-Au Alloys', in 'Optical Properties and Electronic Structure of Metals and Alloys', edited by F. Abelès, North Holland Publ, Corp., Amsterdam, 1966, pp. $565-573$

9 K.E. Saeger and J. Rodies, Metall, 1976, 30, (7), 641-645

10 I.I. Sasovskaya, Pbys. Met. Metall., 1984, 57, (2), 44-48 and Fiz. Metal. Metalloved $1984,57,(2), 261-265$

11 J.P. Jan, W.B. Pearson. Y. Saito, M. Springfield and I.M. Templeton, Phil. Mag. 1965, 12,1271-1291

12 S.S. Vishnumbhatla and J.-P. Jan, Pbil. Mag., 1967, 16, 45-50

13 N.W. Ashcroft and N.D. Mermin, 'Solid State Physics', Holt, Rinehart and Winston, New York, 1976
$14 \mathrm{G}$. Brown, "The Influence of Composition on the Optical Properties of Electrodeposited Gold', Ph.D. thesis, University of Aston in Birmingham, 1980.

15 M. Dettke, Oberfläche-Surface, 1977, 18, (4), 101-102

16 W. Köster and R. Stahl, Z. Metallkunde, $1967,58,768-777$

17 D.J. Arrowsmith and $G$. Brown, Trans. Inst. Met. Finish. , 1983, 61, 1-8

18 O. Loebich, Gold Bull, $1972,5,(1), 2-10$

19 W. Hume-Rothery, R.E. Smallman and C.W. Haworth, "The Structure of Metals and Alloys', The Metals and Metallurgy Trust, 4th Edition, London, 1969

20 E.F.I. Roberts, K.M. Clarke and R. Hunt, Mater. Sci. E.Eng, 1980, 42, $71-80$

21 D.J. Fabian and L.M. Watson, 'Band Structure Spectroscopy of Metals and Alloys', Academic Press, London, 1973

22. N. Parkinson, J. Electrodep. Tech. Soc., 1951, 27, 129-151

23 P.K. Dutta and M. Clarke, Trans. Inst. Met. Finish, 1968, 46, 20-25

$24 \mathrm{M}$. Dettke and R. Klein (Schering AG), 'Method and Bath for Electrodepositing a Violet-Colored Gold-Copper-Bismuth Alloy', U.S. Pat., $4517060,(1985)$

25 F.E. Wang and W.J. Buehler, J. Appl. Pbys., 1971, 42, 4514

26 H.L. Davis, J.S. Faulkner and H.W. Joy, Pbys. Rev., 1968, 167, 601-607

27 E.L. Yates, Aust.J. Phys., 1963, 16, 40-46

28 American Institute of Physics Handbook, 3rd Edition, McGraw-Hill, 1972

29 L.C. Archibald and G. Sanderson, Trans. Inst. Met. Finish., 1977, 55, $149-154$ 